\title{
Lyme carditis and atrioventricular block
}

\author{
Douglas Wan MD, Adrian Baranchuk MD
}

Cite as: CMAJ 2018 May 22;190:E622. doi: 10.1503/cmaj.171452

1 Lyme carditis may be an early manifestation of Lyme disease Lyme disease is a tick-borne bacterial infection (mainly Borrelia burgdorferi) with endemic regions predominantly along the Canada-United States border. In 2016, 987 cases of Lyme disease were reported in Canada. ${ }^{1}$ The heart is involved in up to $10 \%$ of Lyme disease cases, with the development of cardiac tissue inflammation or Lyme carditis. ${ }^{2}$ Nearly all patients with Lyme carditis (90\%) will have atrioventricular block, ${ }^{3}$ which commonly presents with breathlessness, palpitations, dizziness or syncope. ${ }^{2}$

2 A diagnosis of Lyme carditis should be considered in younger patients with severe conduction abnormalities

Patients often present initially with other features of Lyme disease, such as flulike symptoms, arthralgia, neurologic symptoms and erythema migrans, resulting in multiple presentations before cardiac involvement is recognized. Lyme carditis should be considered in patients aged 50 years or younger with severe conduction abnormalities, particularly if they have a history of being outdoors, an insect bite or a migratory rash. Lyme carditis is a clinical diagnosis that can be confirmed with serologic testing. ${ }^{2}$

\section{3}

\section{Atrioventricular block in Lyme carditis can progress rapidly} and be fatal

Cardiac monitoring is critical, and temporary pacing may be needed to manage unstable atrioventricular block until adequate response to antibiotic treatment. ${ }^{4}$

Early treatment with antibiotics may prevent irreversible conduction disease in Lyme carditis

An earlier diagnosis of Lyme disease provides a better chance of reducing or preventing lasting complications. Failure to treat Lyme disease in the early stages may increase the need for implantation of a permanent pacemaker. $^{5}$

Before considering implantation of a permanent pacemaker, clinicians should wait for response to antibiotic treatment for atrioventricular block requiring temporary pacing

High-degree atrioventricular block usually resolves within one week of starting antibiotics. Figure $1 \mathrm{~A}$ shows the reversal of conduction abnormality after treatment with antibiotics. A predischarge exercise stress test to assess atrioventricular conduction during higher heart rates is useful in guiding decisions regarding cardiac pacing. ${ }^{3}$

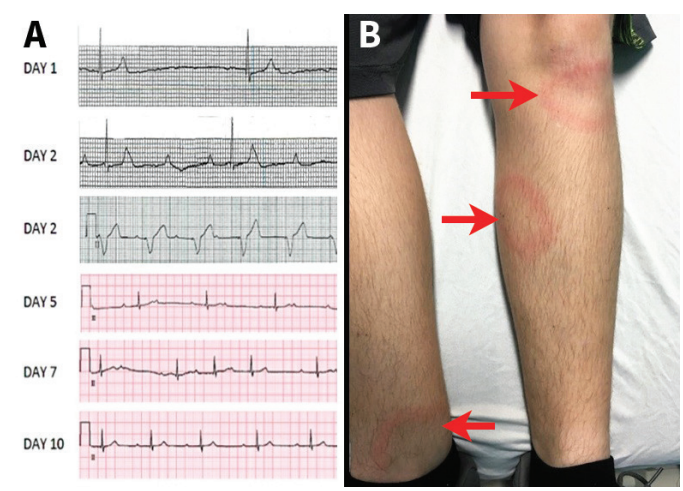

Figure 1: (A) Progression of atrioventricular block from presentation to day 10 of treatment with antibiotics in a 30-year-old man with symptomatic Lyme disease and positive Lyme serology. (Reproduced with permission from Wan and colleagues, ${ }^{3}$ and adapted from Fuster and colleagues. $\left.{ }^{4}\right)(B)$ Erythema migrans in a 14-year-old boy.

\section{References}

1. Surveillance on Lyme disease. Ottawa: Public Health Agency of Canada; 2017. Available: www.canada.ca/en/public-health/ services/diseases/lyme-disease/surveillance-lyme-disease.html (accessed 2018 Feb. 8).

2. Krause PJ, Bockenstedt LK. Cardiology patient pages. Lyme disease and the heart. Circulation 2013;127:e451-4.

3. Wan D, Blakely C, Branscombe P, et al. Lyme carditis and highdegree atrioventricular block. Am J Cardiol 2018;121:1102-4.

4. Fuster LS, Gul EE, Baranchuk A. Electrocardiographic progression of acute Lyme disease. Am J Emerg Med 2017;35:1040.e5-e6.

5. Fu J, Bhatta L. Lyme carditis: Early occurrence and prolonged recovery. J Electrocardiol. 2017 Dec. 14. [Epub ahead of print]. doi:10.1016/j.jelectrocard.2017.12.035

Competing interests: None declared.

This article has been peer reviewed.

The authors have obtained patient consent.

Affiliation: Department of Medicine, Division of Cardiology, Queen's University, Kingston, Ont.

Correspondence to: Adrian Baranchuk, barancha@kgh.kari.net 